\title{
The messy social lives of objects: inter- personal borrowing and the ambiguity of possession and ownership
}

Article

Accepted Version

Jenkins, R., Molesworth, M. and Scullion, R. (2014) The messy social lives of objects: inter-personal borrowing and the ambiguity of possession and ownership. Journal of Consumer Behaviour, 13 (2). pp. 131-139. ISSN 1479-1838 doi: https://doi.org/10.1002/cb.1469 Available at https://centaur.reading.ac.uk/79212/

It is advisable to refer to the publisher's version if you intend to cite from the work. See Guidance on citing.

To link to this article DOI: http://dx.doi.org/10.1002/cb.1469

Publisher: Wiley

All outputs in CentAUR are protected by Intellectual Property Rights law, including copyright law. Copyright and IPR is retained by the creators or other copyright holders. Terms and conditions for use of this material are defined in the End User Agreement.

www.reading.ac.uk/centaur 
Central Archive at the University of Reading

Reading's research outputs online 


\section{The messy social lives of goods: Inter-personal borrowing and the ambiguity of possession and ownership.}

Proposed short title:

Borrowing and the ambiguity of possession and ownership

\section{Authors:}

Rebecca Jenkins*, ECCG, The Media School, Bournemouth University, Talbot Campus, Fern Barrow, Poole, BH12 5BB. UK. rjenkins@bournemouth.ac.uk. Phone: 01202965202. Fax: $01202962736 *$ Corresponding author for all contact and checking proofs.

Mike Molesworth, ECCG, The Media School, Bournemouth University, Talbot Campus, Fern Barrow, Poole, BH12 5BB. UK. mmolesworth@bournemouth.ac.uk. Phone: 01202 965632. Fax: 01202962736

Richard Scullion, ECCG, The Media School, Bournemouth University, Talbot Campus, Fern Barrow, Poole, BH12 5BB. UK. rscullion@bournemouth.ac.uk. Phone: 01202965350. Fax: 01202962736

\section{Biographies:}

Rebecca Jenkins (Becky) is Lecturer in Consumer Culture and Behaviour at Bournemouth University. She is part of the Emerging Consumer Cultures Research Group (ECCG). Her $\mathrm{PhD}$ was a study of how consumption gives shape to everyday imagining. She is currently developing papers and further projects based on her $\mathrm{PhD}$ thesis and pursuing projects on the consumerisation of the wedding.

Mike Molesworth is Senior Lecturer in Consumer Culture and Behaviour and Interactive Media at Bournemouth University. Also part of the Emerging Consumer Cultures Research Group, his research interests include online consumer behaviour, digital virtual consumption, the consumer imagination and everyday practices.

Richard Scullion is a Senior Lecturer in Advertising and Marketing Communications and member of the Emerging Consumer Cultures Group at Bournemouth University. His research interests include a variety of cultural practices and experiences including politics, citizenship, consumption and advertising. 


\title{
The messy social lives of goods: Inter-personal borrowing and the ambiguity of possession and ownership.
}

\begin{abstract}
In this paper we position inter-personal borrowing as a form of non-market mediated access based consumption, a distinct form of exchange that is complex and inherently ambiguous, and a form of consumption that is under researched. We argue that the temporary transfer of possession is a defining feature of borrowing, which causes ambiguity to arise out of an object being simultaneously active in more than one network, such that it assembles multiple realities; a good can often be different things to different people at the same time. From our empirical data we establish three emergent themes within a narrative of borrowing. First we note that the boundaries of ownership and possession easily become blurred. Second, we find that borrowers make appropriation attempts, such that borrowed items may be temporarily treated as mundane objects, before being re-sacralised by the borrower and then re-appropriated by the lender. Finally, we acknowledge the vitality of borrowing and lending as part of social relationships, noting that ultimately relationships construct and are constructed by practices of borrowing (and lending). The unique characteristics of borrowing identified in our study offer an opportunity to better understand the ambiguity, or 'messiness', within an object's social life that is not contained within existing work on the biography of goods.
\end{abstract}

Key words: access, biography of goods, borrowing, ownership, possession, relationships 


\section{The messy social lives of goods: Inter-personal borrowing and the ambiguity of possession and ownership.}

\section{Introduction}

In this paper we concern ourselves with inter-personal borrowing (from here on referred to simply as 'borrowing'); a pervasive form of non-market mediated access based consumption and a distinct form of exchange. We argue that complexities revealed in borrowing, in terms of the boundaries between possession and ownership and social relations, offer an opportunity to better understand the ambiguity, or 'messiness', within an object's biography.

Ambiguity has commonly been considered a derivate of the decision making process within consumer behaviour (Kahn and Rakesh, 1988), and more recently connotes symbolic meanings attached to consumption (Elliot, 1999). Here, we also embrace both the sociological perspective of ambiguity concerning rules and social convention (Becker, 1997) and the cultural view of instability of classification (Grossberg, 2009). From Law's (2004) perspective we note that ambiguity may result from an object being simultaneously active in more than one network such that it assembles multiple realities. In this case, for example, we might recognise that a borrowed item is always also a lent item.

Consumer culture research has previously documented how we make sense of possession and ownership as a good graduates from a commodity to singularised possession and from the latter, back to a commodity state or an unwanted possession (Appadurai, 1986; Belk, 2010; Epp and Price, 2010; Kopytoff, 1986; Lastovicka and Fernández, 2005). Emerging concerns have also seen material objects as facilitating and modulating our relationships to others, either as means to initiate and maintain relationships (Douglas, 2001; Douglas and Isherwood, 1979; Mauss, 1925/1967; Miller, 1987), to memorialize significant meaningful relationships (Belk et al., 1989; Csíkszentmihályi and Rochberg-Halton, 1981), or as a vehicle to make visible existing social hierarchies and arrangements (Douglas, 2001; Douglas and Isherwood, 1979). However, within these enquiries, practices of borrowing and lending are remarkably absent.

Consumer research tends to consider the movement of objects in terms of their changing status. Upon aquisition a good may be singularized or appropriated undergoing a transformation from commodity to possession and becoming incorporated into the owners world of meaning (Kopytoff, 1986; Miller, 1987) via possession or decommoditization rituals (Coupland, 2005; Kopytoff, 1986; McCracken, 1988; Rook, 1985; Sherry and McGrath, 1989). Once singularised, possessions are valued for their personal meanings, whilst any exchange value remains latent (Kopytoff, 1986). However the material good's status as a singular possession is by no means permenant, and other rituals and social relations might later recommodify the good as it returns to the commodity sphere. We argue that this biography is incomplete; that there may be more activities and experiences taking place in relation to the social lives of material goods 'in-between' their status as singularised possession and re-commodification - an inherently more ambiguous space and phase. Although Kopytoff's (1986) work highlights the ambiguity of objects in their ever changing biography, what we highlight here is their ability to be more than one thing at the same time as their biography unfolds. We consider borrowing as a distinct activity that has its own set of characteristics, rituals and negotiations that impacts the social lives of many different types of objects. We also note that borrowing may invite us to consider a multiplicity in an object's status; that as we classify goods, we might recognise that they are sometimes or often 
different things to different people at the same time. We aim to develop the field of borrowing by offering insights drawn from empirical work.

In previous research ownership is relatively clear; commodities bought are incorporated through a series of practices or rituals - as private, personal possessions they become extensions of their owners (Belk, 1992), as shared goods they are owned by family or 'in group' members (Epp and Price, 2008; 2010) and as accessed goods they are used and enjoyed but not owned (Bardhi and Eckhardt, 2012; Chen, 2009). We argue that while biographical approaches to goods have generally been linked to individual or family identity projects (e.g. Epp and Price, 2008; 2010) where possession of an item and its ownership is well-defined, in borrowing, ownership and possession are made messy by episodes of temporary possession marked by simultaneous appropriation by more than one person. The value of understanding inter-personal borrowing then, lies in the belief that it constitutes a significantly distinct form of non-market exchange that gives us new insights. These include what temporary transfer of ownership reveals about how individuals relate to borrowed objects, whether or how a temporary owner can alter an item's biography and the role of the good in mediating embedded social relations of borrower and lender.

\section{Conceptualising inter-personal borrowing}

In the following section we describe the characteristics of borrowing in relation to other forms of exchange, noting that it has its own set of characteristics and conventions that mark it as distinct. We find it useful to reflect on Belk's (2010) family resemblance analysis of sharing, gifting and commodity exchange to consider the ways in which borrowing may differ from, and be less precise than, other forms of exchange.

Borrowing can be positioned as a non-market mediated form of access, based on two core principles; the temporary nature of possession (limited time with/access to an object for the borrower) and the absence of ownership (possession without ownership for the borrower) (Bardhi and Eckhardt, 2012). However, as a more collaborative activity (Botsman and Rogers, 2010) complexities arise out of the social and personal nature of borrowing, which differ from and extend the concept of market-mediated access based consumption. Our understanding of the biographies of goods may be improved when we explore the various facets of inter-personal borrowing because it is through appreciating complexities that we know more about our attachment to goods, their social lives and, how goods mediate social relationships.

Belk's (2007: 126) definition of sharing; the 'process of receiving... something from others for our use' and of lending; 'distributing what is ours to others for their use' highlights the similarities between sharing and borrowing, indeed for Belk (2006; 2007) lending and borrowing are included in the broad definition of sharing. Yet it is also possible to make distinctions between the two forms of exchange. Such distinction resonates with Tinson and Nutall's (2007) separation of sharing and borrowing, where inter-familial borrowing is positioned as quite a different concept to sharing in that it is regarded as voluntary, and contains a more complex, or at least different system of rules than sharing. Borrowing identifies two parties ('lender' and 'borrower'), which leads to the key factor differentiating it from other forms of exchange and access-based consumption; the nature of the transfer (and non-transfer) of ownership and possession.

Although commodity exchange and gift giving also involve a transfer of ownership, and sharing involves joint ownership (Belk, 2010), borrowing involves a temporary transfer of possession, in which the borrower does not become the legal 'owner'. This temporality 
places ambiguity onto the borrowed object due to the unstable environment in which it is experienced (Kopytoff, 1986; Slater, 2002). A borrowed good is a liminal entity, it is 'neither this, nor that' - neither entirely mine nor yours and therefore this liminality is inevitably ambiguous (Turner, 1977). Temporary transfer of possession influences the person-object relationship in ways that generate uncertainty. Adding to the imprecise character of borrowing we recognise the potential for a double obligation in the practice - to return the object and to return the favour by allowing the lender to borrow something in the future.

\section{Person-object relationships and borrowing}

'The mode of consumption shapes consumers' relationship to products and services and their preferences, values and desires' (Bardhi and Eckhardt, 2012: 882). In comparison to ownership, access produces a different object-self relationship and the rules that govern and regulate this relationship are dissimilar (Bardhi and Eckhardt, 2012; Chen, 2009; Rifikin, 2000). Bardhi and Eckhardt's (2012) study of access based consumption found that 'the work of consumption' is absent in this model of market-mediated access, in that consumers do not engage in appropriation practises with accessed objects. In the context of their study, perceived ownership was not experienced; objects did not form even a temporary extension of the self due to limited time with the object, fear of contamination due to others' use of it, and especially the involvement of the marketplace. However, if something is accessed over a longer period of time then a sense of ownership may be experienced and appropriation practices follow (Strahilevitz and Loewenstein, 1998). Despite not legally owning it, individuals invest energy in the object such that it becomes meaningful to them (Belk, 1988).

In market-mediated access the over-arching object-self relationship is one of usevalue (Bardhi and Eckhardt, 2012). Objects are 'nobody's', but everyone's to use. However, borrowing's pro-social nature suggests a less straightforward relationship. In borrowing, person-object relations may differ because there is no market mediation and instead a wide range of relations with the owner (lender). For example, it seems fair to assume that a singularised object may be difficult to appropriate by a borrower; considered to be contaminated by the owner, or the borrower may be at fear of contaminating someone else's possession. However, considering Appadurai's (1986) work regarding the likelihood of singularisation taking place, we see that there is potential for the borrower to singularise an item at a time when an object's status is unstable or ambiguous, consequently, the sacred meaning to the lender is put at jeopardy. Although singularisation is desirable for an owner, and not for market-mediated access, in borrowing things are less clear. We now consider the role of goods in mediating social relationships, applying this to the case of borrowing.

\section{Social relationships and borrowing}

The temporary exchange and use of goods features as a mediator of social relationships, with borrowing being partly understood in terms of 'cultural norms' (Bardhi and Eckhardt, 2012; Tinson and Nuttall, 2007). These serve to distinguish what is socially accepted or not. Importantly, Tinson and Nuttall (2007) emphasise the ambiguous nature of borrowing's blurred rules of ownership and structure by introducing the idea of 'covert borrowing' (whereby individuals borrow without permission). This plays on the fact that borrowers may be aware of social norms, but sometimes choose to ignore them. Other behaviours in relation to the treatment and use of the borrowed item may also occur that are not necessarily regarded as appropriate. Both of these qualities add to the messiness of borrowing.

In terms of market-mediated access, an individual's relationship with and behaviour towards others is marked by anonymity (Bardhi and Eckhardt, 2012). In borrowing, 
however, it is on a personal - and often well known (e.g. a friend or relative) - basis. Indeed, this relationship is likely to be important for borrowing to take place. For instance the degree of trust between borrower and lender and experience in borrowing something in the past, all contribute to its inherent 'in flux' social arrangement. Borrowing (and lending) is always intersubjective.

Pro-social forms of access have been found to generate a range of social relationships, for example Ozanne and Ozanne (2011) investigated not-for-profit toy libraries and found consumers to be sensitive and responsible towards each other and the objects they are accessing. In contrast, Bardhi and Eckhardt's (2012) study finds car scheme users to be opportunistic, in that they look out for themselves at the expense of the object and of other (anonymous) users. Because of the often close personal relationship between lender and borrower we might expect borrowers to be responsible and sensitive towards the object and the lender, however, research into sharing and borrowing between sisters, indicates that even within this close relationship such responsibility or care is not always displayed (Tinson and Nutall, 2007). All of this illustrates the multiple interpretations of practice ascribed to acts of borrowing and so this is certainly an area that is in need of clarification via empirical research.

Prior research touches only lightly on borrowing, usually in the context of other forms of exchange. There is little attempt to understand its distinct characteristics that afford it a deep sense of ambiguity.

\section{Methods}

This research combines two datasets. One study looked at lending and borrowing in the context of first year undergraduates living in shared accommodation and the other looks specifically at the experience of borrowing across a broader sample, ranging from students to middle aged mothers. Both studies used in-depth interviews conducted in participants' homes and in total the data collected amounts to over 40 hours across 24 interviewees.

In-depth interviews drew on principles of phenomenology, in that we were interested in collecting detailed stories that focused on lived experiences of borrowing and lending, together with broader stories about participants' lifeworlds (Thompson, 1997; Thompson, Locander and Pollio, 1989; Van Manen, 1990). We should note here that, at the time of interviewing, the student group were actively negotiating new social relationships and living arrangements (they were in shared accommodation with peers for the first time), though they contrasted these recent experiences with previous lending and borrowing experiences (with family and established friends).

All interviews were conducted in the participant's homes and we encouraged them to show us the borrowed and lent items that they talked about to help us see and better understand how such goods were integrated into their homes and lives. This in particular often highlighted a discrepancy between what individuals said and what they actually do. Thus we find a tendency to initially offer a rationalised presentation of themselves as borrowers and lenders. Not only did they talk about wanting to seem like a 'good' person in their lending and borrowing, but in their accounts to us they wanted to be seen this way, despite later 'confessions' that they sometimes were not good borrowers (or lenders). It became apparent that the individuals we spoke to were very clear about what they would and would not lend/borrow as well as who they would lend to or borrow from. 
Interviews were transcribed and idiographic profiles of individual participants were produced, emerging global themes were then identified (Thompson, 1997; Thompson, Locander and Pollio, 1989) and synthesised amongst the team of researchers. Overall, our data highlights that accounting for borrowing encourages participants to think carefully about both their possessions and their relationships (actual and ideal) with others.

\section{Findings and analysis}

Within our data we identify a narrative that describes the practice of borrowing, from the perspectives of both borrower and lender. It can be seen as starting with an individual's thoughts towards borrowing something, through to the return of a borrowed item and the reincorporation of that item for the lender. Within this narrative we establish three themes. First, we find that the boundaries of ownership and possession easily become blurred. While borrowers can acknowledge the legal owner of a borrowed item (and recognise that it is not them), they may treat them as if they were owned. This links to the second theme, the apparently necessary appropriation attempts by borrowers such that borrowed items may be treated as mundane objects. Finally we acknowledge the vitality of borrowing and lending as part of social relationships; that ultimately those relationships (actual and desired) construct and are constructed by practices of borrowing (and lending).

\section{Blurred boundaries of ownership}

Whilst the literature asserts that access means possessing without owning and market mediated forms do not tend to provoke a desire to own or treat an item as if it is owned (Bardhi and Eckhardt, 2012), contradictions emerge in our data when it comes to possession and ownership. Although the idea of a 'legal owner' was acknowledged, the boundaries of ownership were not clear-cut, such that this very idea - so central to capitalist object relations - became problematic. Participants expressed how they often felt a sense of burden when borrowing objects, and thus a desire or need to treat borrowed objects carefully, as sacred to the owner, and we certainly saw evidence of borrowers taking great care of borrowed items, especially from people they don't know very well. Yet at the same time they revealed that borrowed items would often end up integrated with their own belongings and treated as 'mundane'.

For example, Diane, a middle-aged mother of three, told us that she did not enjoy borrowing, however, on the rare occasion that she did borrow something she explained how she would treat these items carefully and keep them separate from her own belongings;

I do tend to keep those (DVDs) separate from our own, for fear of forgetting to give them back probably, or whose they were [...] They tend to sit on one side [...] I will put it specifically away from the DVDs.

This was also the case for Craig. Craig has recently become a mature student and lives with three other male students. Throughout the interview, Craig continually expressed his discomfort towards borrowing stating:

So I always make sure anything I have borrowed I use it for that as soon as possible and then I give it back because I don't like having it....

We note here that such explanations were often accompanied by a recognition that this is how individuals would expect people they lent to to behave. We might therefore assume that 
borrowers may make a concerted effort not to singularise a borrowed item because they know it is not actually theirs, and wouldn't want this of their lent items. However, returning to Diane's story, when asked to show the interviewer the DVD mentioned, it was found integrated with all her other DVDs placed in alphabetical order. This incident was not isolated either, a similar situation occurred with a hedge trimmer about which she said 'we are very careful with it. And we store it very carefully. Unlike the rest of our stuff which is just heaped in!'. In the garage, however, the hedge trimmer was not stored as explained in the interview, but was on the floor scattered amongst other items belonging to the family. The boundaries of ownership have been blurred not only by Diane's practices but also in her hesitant and defensive response to encountering this contradictory situation.

Likewise, Craig described how some borrowed DVDs 'became' his:

But I borrowed them (DVDs) when I was down there (in Brighton) and brought them back [...] They have just kind of ended up being mine.

We see that people think of themselves as a certain kind of borrower and hold a belief that they act in ways appropriate to social norms relating to the treatment of someone else's belongings. In practice, however, borrowing does not necessarily play out in this manner. They think about and enact borrowing differently. This is suggestive of an imagined or assumed person-object relationship characterised by a separation of self from object. In other words, borrowers are aware of and sensitive to the person they have borrowed from (and the legal status of a borrowed good), yet don't always enact this ideal relationship when they use a borrowed item. In particular, closeness to a lender, and knowledge of their relationship to a good, may inform actual use. Knowledge that the owner doesn't treat an item well, may result in a familiar borrower treating it similarly.

\section{Appropriation, re-sacralisation and reincorporation}

Borrowers may end up appropriating borrowed items into their own belongings. They may then have to re-sacralise borrowed objects by removing evidence or aspects of their own relationship with the object before returning it to the owner. On return, further 'work' is conducted by a lender to reincorporate the object back into their possession. There are therefore three components to consider under this theme; appropriation by the borrower, resacralisation by the borrower and re-incorporation by the lender.

\section{Appropriation}

Borrowers may appropriate or 'de-sacralise' items through rather accelerated, excessive and even abusive use. We regard this as a method of appropriation because the borrowed item is not treated as sacred but becomes profane in the hands of the borrower. This behaviour further contradicts the belief that individuals hold with regard to their borrowing behaviour. For example, Felicity, a student who has a keen interest in fashion, talks about spilling things on a scarf she regularly borrows;

I was absolutely petrified! But I still borrowed it... There were times where I had a toothbrush and I was trying to get things out [...] It had so much embellishment on it that you couldn't tell things. And she couldn't tell what she'd done and what I'd done.

Although Felicity told us she was nervous about borrowing such a delicate item she still 
behaved in an abusive manner towards it, dismissing its sacredness. She left marks and stains on the item - contaminating it - justifying this by explaining that she felt that the lender had also treated it similarly. She went on to state:

I think I'd feel different though if someone actually bought it for me! I know that sounds weird but... Yeah, if she turned round and gave me that shawl then I'd think that was amazing.

Here, not only do we see how Felicity has appropriated this specific item through her abuse and contamination of it, but that its very biography allows this appropriation to take place with ease. This resonates with Kopytoff's work (1986) emphasising the importance of an item's perceived biography even in borrowed goods. The borrowed item is not thought of as a gift, for example.

We also heard stories of individuals using borrowed items more than they use their own so as to 'make the most of it' before having to return it. The temporariness of possession is acknowledged here and may drive the exploitative use of an object, where use-value is maximised. Participants also talked of 'adopting' borrowed objects. Sometimes this was inadvertent, such as when an object had been borrowed for so long that the lender authorised the borrower to keep it. At other times something had been borrowed for so long that adoption was more implicitly felt by the borrower, whilst in some instances the borrowers developed ways of extending the length of temporary possession. Rosie provides a good illustration of this.

I borrowed a bag, from my sister, which I just kind of adopted, as my own and then just never returned it. I just really liked it [...] I just kept myself in it, so that she couldn't get to it. I just claimed it. And just kind of said 'This is now mine, so I'll keep my things in it.

By leaving her personal belongings in the bag, she made it harder for the lender to reappropriate it. This is Rosie extending temporary ownership with the possible goal of permanent ownership. Although this may be an extreme case, it helps to demonstrate the scope with which borrowers can appropriate.

\section{Re-sacralising}

Borrowers attempt to re-sacralise borrowed objects by undertaking cleaning, mending and erasing traces of use before returning it to a lender. Here we see evidence of social norms returning to the fore as individuals feel the need to be seen as a good borrower once again. Amanda, a final year undergraduate, explains how she removes signs of her use of clothing:

If you wash it with detergent, it will smell of detergent, it won't smell like you. I think you want to give it back in the same condition, or in a nicer condition. I think if something smells freshly washed, it's nicer for them to receive.

In another example, Jack tells a story of covertly borrowing a bike and trying to remove the evidence of his use:

It was really muddy when I rode it, so I made a conscious effort to clean it and returned it in a better state then when I took it. 
In these stories, the cleaning of an object attempts to remove signs of appropriation - what has been added to its biography via the process of borrowing - and can be interpreted as sacralising the object in order to make it like the borrower believes it used to be. For the borrower the separation of object with its owner (the lender) that allowed for appropriation is ended and obligations to the lender foregrounded again.

\section{Reincorporation}

The lender may then re-appropriate (reincorporate for oneself) the object, especially when signs of appropriation by the borrower have not been sufficiently removed. By lending something the lender faces the possibility that their possession may be singularized by a third party and participants articulated this risk. Just as second hand goods may be perceived as contaminated by the previous owner (Belk, 1988; 2010; Belk et al., 1989; Gregson and Crewe, 2003), lent items may be perceived as contaminated by the borrower. Stories of reincorporation often occurred when a lent object had been returned in a different condition to when it was lent out. For instance, Betty spoke about how weird her car felt once a friend had returned it after using it for one day - seats had to be readjusted, settings changed and the paraphernalia they left behind, in this case a Madagascan Vanilla air freshener, had to be removed.

This process of appropriation (often in an accelerated manner), resacralisation and reincorporation are, in effect, the practices of ambiguity. The social and cultural norms surrounding them are less clear than in other forms of consumption. Indeed the certainty of a possession granted by legal ownership and singularisation is problematized here in that borrowing occurs within the nuanced and fluid context of social relations.

\section{Mediating social relationships through borrowing and lending}

Although our focus here is the messiness of the status of goods when lent and borrowed, we finally want to acknowledge the importance of relationships in the practices

It was clear from our conversations with people that a need for reciprocation is apparent when borrowing. Like gift giving (Mauss, 1990), but less routinized, or ritualised, borrowing may seem non-reciprocal, but in practice is expected. Further, borrowing has a double obligation; not only is borrower expected to lend back in the future - as, in practice, we would be expected to reciprocate gift giving - but we should return the lent object. Here Georgina articulates a vague sense of desired reciprocation:

I say if you lend something to someone you're more likely to get something back in return later on if you need something, so it only works in your favour I think anyway...

Later however, she makes it clear that, conditions apply:

...we were just chatting and then she was talking about the work she has to do so I offered my laptop again, and I gave her the charger as well because I knew I was running low on battery. I asked her 'are you going to be around tomorrow' and she said she has to be out by 8.00 so she said she'd leave it in the kitchen, so it was here when I woke up. So you've got to plan when you get stuff back as well...

Unlike a gift, borrowing and lending may require a more complex set of explicit negotiations over use and return, as well as implicit expectations for reciprocation. 
Borrowing is therefore involved in negotiating relationships. Although participants often didn't know about the sorts of relationships they aspire to form, the types and strengths of such relationships, or where they might lead, they demonstrated a desire to fit in, to be liked, and for others to think highly of them.

Relationship building or alliance formation via borrowing and lending incorporates a number of specific issues. Motivations for lending varied. For example it was expressed as a way to demonstrate care or empathy and as a simple recognition that the other person is in need. Borrowing was presented as an act that shows you can be trusted; lending shows you reciprocate that trust.

It was also apparent that borrowing (and lending) are learned practices. Manners and an understanding of our relationship with others suggest that there are cultures of lending and borrowing that we are socialised into. Here an individual's personal biography also impacts on the ways they might use goods to build or maintain relationships. Positive experiences of borrowing and lending make it easier to do so again. People may also have bad experiences, including where they have borrowed or lent something that has been either lost or damaged. Thus it was clear in the stories we heard that such experiences were used to reflect and learn.

Our relationship with the people we borrow from- or choose not to - have a significant impact upon such practices, knowledge of the other people involved makes borrowing more likely and less stressful. Borrowing then is a form of bonding by demonstrating similarities through material goods; people tend to engage with others who have common characteristics and personality traits - a way of reducing the ambiguity of the act. Nonetheless, borrowing generates tensions for an individual because such practices create situations where some mutuality of effort is required. Such tensions include; when a person does not want to lend an item and is faced with having to say no, and where an issue emerges as a result of lending or borrowing. It was evident that even if you trust someone you might still not lend an item because you wouldn't want to have to ask for a replacement if it was lost or broken. Participants explained that by asking for the return of an object a relationship might be damaged.

Reluctance to approach the borrower may centre on the transformative potential of such acts; from friend-to-friend relationship, to a lender-to-borrower relationship and back again. For example, here a participant is talking about his watch:

I got mine for my $18^{\text {th }}$ birthday from my nan and granddad and it's quite expensive as well so if I broke it I'd feel responsible. If I lent it out to someone and they lost it and broke it I'd be gutted I think...I know I wouldn't be able to afford to buy a new one, maybe that's it as well. It'd cause an argument if they lost it...Yes, it'll cause some sort of issue that I wouldn't want to have so I wouldn't let it happen.

The individual is not merely trying to protect the material object involved, but crucially to preserve the relationship with others by avoiding potentially tense situations.

\section{Discussion}

Borrowed goods blur the boundaries between possession and ownership. Whilst the legal owner is acknowledged, and borrowers recognise that there are social norms or customs associated with borrowing (Barhdi and Eckhardt, 2012; Tinson and Nutall, 2007), when in their possession, borrowers may treat the borrowed items as if they were their own goods. 
This practice of separating their relationship with the good from their idealised view of what it is to be a 'good borrower', is based on a projection of feeling towards their own lent items and their relationship with the lender. It seems that once mixed with existing possessions, objects are no longer sacred - to be sacred they need to be separated. The blurring of boundaries in borrowing practice helps place an object into an ambiguous status, which according to Appadurai (1986) leaves the object exposed to attempts to singularize it, which we also find evidence of.

In terms of singularisation or appropriation of borrowed items, there are contrasts with market-mediated access research which finds consumers are likely to treat accessed objects differently to their own - not engaging in appropriation processes (Bardhi and Eckhardt, 2012). We, however, find that borrowers may treat goods as if they are their own yet also know this is not quite the case - an inherently ambiguous cognitive state. In some of the more extreme cases of appropriation the notion of opportunism, as found in Bardhi and Eckhardt's (2012) study, is evident.

The re-sacralisation process tells us something about the social norms associated with practices of borrowing, as well as the relationship between lender and borrower. Although this offers structure to the process, as we have demonstrated, this is far from ridged. Although the abusive treatment of borrowed goods is similar to market-mediated access (Bardhi and Eckhardt, 2012), the efforts individuals go to in order to re-sacralise is in contrast to marketmediated forms, and due to the personal relationship between borrower and lender. The concept of 'divestment rituals' (McCracken, 1986), where possessions exchanged are emptied of their prior meanings, erasing personable qualities, easing dispossession of the object, is highly resonant here. Despite attempts to re-sacralise and remove evidence of use, we find that lenders may still have to make efforts to re-incorporate items into their possession. Like other singularizing rituals (Lastovicka and Fernández, 2005; McCracken, 1988) borrowing and lending involves physical processes that help re-incorporate lent possession and so preserve sacredness (Belk et al., 1989).

Apart from the obvious use-value of borrowed goods, borrowing is always about relationships with others. Such practices are manifestations of how we demonstrate empathy, trust and connection through material objects. Indeed the double obligation - the angst regarding negotiations over what can and cannot be lent and borrowed, to whom, when and how goods are to be returned - makes lending practice potentially more meaningful than the gift. Our study alerts us to how lending is part of the work we enact in our quest for negotiation, co-construction and the give and take of everyday life.

Social relations as reputation are formed on the basis of practices of borrowing, lending and returning items (or not). This may be seen in Appadurai's (1986) discussion of Kula - primitive societies where objects are exchanged from one individual to another with the individual gaining or losing reputation as the object travels. The extent of harmony achieved in the 'movement of possessions' through borrowing affects both an individual's reputation and the state of relationships with others. The stories we heard were characterised by diversity, from family borrowing where rules were implicit and deeply flexible, through to borrowing from a tutor where extraordinary care and attention was paid to the object. This variation in borrowing practice further contributes to its ambiguous status.

\section{Conclusion}

Our attempts to conceptualise borrowing has demonstrated that it is a sufficiently distinct and complex form of exchange that tells us more about aspects of consumption little documented 
to date in terms of the social lives of goods. In terms of the biography of goods we see that the act of borrowing (and lending) extends our knowledge and understanding of the always in flux nature of possessions, but perhaps another way of seeing this is that the status of goods has a multiplicity that is often 'manifest absent' in existing categorisations (Law 2004). Goods are usually seen as being in one state or another (commodity, or singular; sacred or profane; owned, or not) because the focus in such categories tends to be the individual, or single network (for example the home). Borrowing (and lending) shows us that goods may also be two things at once as they inhabit different networks at the same time. It also illustrates both the importance of the legal category of 'ownership' in how goods are understood, but also the tenuous nature even of this taken for granted status. Looking at goods through the lens of borrowing helps us to recognise their movement within and between different networks and this idea may be applied to other situations to enrich our understanding of the biographies of goods. In other words, borrowing reminds us of the 'messiness' of the biography of goods that requires further elaboration of all the different networks that any one good may be active in at the same time. In addition, in order to yield a greater level of nuance to our understanding of the role of borrowing in mediating social relationships, more detailed research into the different kinds of contexts in which borrowing takes place - family, friends, colleagues, neighbours, community-level, is needed.

\section{References}

Appadurai, A. 1986. The Social Life of Things. Cambridge: Cambridge University Press.

Bardhi, F., and Eckhardt, G. 2012. Accessed based consumption: the case of car sharing. Journal of Consumer Research. Vol 39. (December): 881-898

Becker, H. 1997. Outsiders: Studies in the sociology of deviance. Simon and Schuster.

Belk, R. W. 1979. Gift Giving Behavior. Research in Marketing, Vol. 2, Jagdish Sheth (ed). Greenwich CT: JAI: 95-126.

Belk, R.W. 1988. Possessions and the Extended Self. Journal of Consumer Research, 15 (2): 139-168.

Belk, R.W. 1992. Attachment to possessions, in Human Behavior and Environment: Advances in Theory and Research, vol. 12, ed. I. Altman and S. Low. New York: Plenum

Belk, R.W. 2006. Ownership, Ego and Sharing. Proceedings of Conference "To Buy or to Rent." Paris: ESCP-EAP, 9.

Belk, R.W. 2007. Why Not Share Rather than Own? Annals of the American Academy of Political and Social Science, 611 (May): 126-40.

Belk, R.W. 2010. Sharing. Journal of Consumer Research, 36 (February): 715-734.

Belk, R.W., Wallendorf, M., and Sherry, J. 1989. The Sacred and the Profane in Consumer Behavior: Theodicy on the Odyssey. Journal of Consumer Research, 15 (June): 1-38.

Botsman, R. and Rogers, R. 2010. What's Mine is Yours: The Rise of Collaborative Consumption. New York: Harper Collins 
Chen, Y. 2009. Possession and Access: Consumer Desires and Value Perceptions Regarding Contemporary Art Collection and Exhibit Visits", Journal of Consumer Research 35 (April): $925-40$

Coupland, J. C. 2005. Invisible Brands: An Ethnography of Households and the Brands in Their Kitchen Pantries. Journal of Consumer Research Vol. 32 (1): 106-119

Csikszentmihalyi, M. and Rochberg-Halton, E. 1981. The meaning of Things. Domestic Symbols and the Self. Cambridge: Cambridge University Press.

Douglas, M. 2001. Why do people want goods?, In Consumption, Critical Concepts in the Social Sciences, Daniel Miller (ed.). Routledge: London: 262-271

Douglas, M. and Isherwood, B. 1979. The World of Goods, Routledge: London.

Elliott, R. 1999. Symbolic meaning and postmodern consumer culture. In Douglas Brownlie (ed) Rethinking marketing: towards critical marketing accountings. Sage: Gateshead: 112125 .

Epp, A. and Price, L. 2008. Family Identity: A Frame- work of Identity Interplay in Consumption Practices. Journal of Consumer Research, 35 (June): 50-70.

Epp, A. and Price, L. 2010. The Storied Life of Singularized Objects: Forces of Agency and Network Transformation. Journal of Consumer Research, 36 (February): 820-837.

Gregson, N. and Crewe, L. 2003. Second-Hand Cultures. Oxford: Berg.

Grossberg, L. 2009. Cultural studies: What's in a name? (One more time). In R. Hammer \& D. Kellner (Eds.), Media/cultural studies: Critical approach: 25-48). Peter Lang: New York.

Kahn, B. and Rakesh, S. 1988. Modeling ambiguity in decisions under uncertainty. Journal of Consumer Research 15 (2): 265-272.

Kopytoff, I. 1986. The cultural biography of things: commoditization as process. In Appadaurai, A., (ed) The social of life of things. Cambridge: Cambridge University Press.

Lastovicka, J. and Fernández, K. 2005. Paths to Disposition Divestment: The Movement of Meaningful Possessions to Strangers. Journal of Consumer Research, 31 (4): 813-823.

Law, J. 2004. After Method. London: Routledge.

Mauss, M. 1925/1967. The Gift: Forms and Functions of Exchange in Archaic Societies, ed. Ian Cunnison, New York: Norton.

McCracken, G. 1986. Culture and consumption: A theoretical account of the structure and movement of the cultural meaning of consumer goods. Journal of Consumer Research 13 (June) 71-84

McCracken, G. 1988. Culture and Consumption. USA: Indiana University Press

Miller, D. 1987. Material Culture and Mass Consumption. Oxford: Basil Blackwell

Ozanne, L.K., Ozanne, J.L. 2001. A Child's Right to Play: The Social Construction of Civic Virtues in Toy Libraries. Journal of Public Policy \& Marketing. 30 (2): 264-278. 
Rifkin, J. 2000. The Age of Access: the New Culture of Hypercapitalism, Where All of Life Is a Paid-for Experience. New York: J.P. Tarcher/PutnaM

Rook, D. W. 1985. The Ritual Dimension of Consumer Behavior. Journal of Consumer Research, 12 (December): 251-264

Sherry Jr., J. F. and McGrath, M. A. 1989. Unpacking the holiday presence: A comparative ethnography of two gift stores. In: Interpretive Consumer Behaviour, Hirschman, E. C., eds, Provo, UT: Association for Consumer Research: 148-167.

Slater., D. 2002. Markets, materiality and the 'new economy'. In Metcalfe S, Warde, A (eds.) Market Relations and the Competitive Process Manchester University Press: Manchester: 95113

Strahilevitz, M. A., and Loewenstein, G. 1998. The effect of ownership history on the vauation of objects. Journal of Consumer Research 25 (3): 276-289

Tinson, J. and Nuttall, P. 2007. Insider Trading? Exploring Familial Intragenerational Borrowing and Sharing. European Advances in Consumer Research, 8: 41-42.

Thompson, C. J. 1997. Interpreting consumers: A hermeneutical framework for deriving marketing insights from the texts of consumers' consumption stories. Journal of Marketing Research 34 (4): 438-455.

Thompson, C. J., Locander, W. B and Pollio, H. R. 1989. Putting consumer experiences back into consumer research: The philosophy and method of existential-phenomenology. Journal of Consumer Research 16 (September): 133-146.

Turner, V.W. 1977. Process, system, and symbol: a new anthropological synthesis. Daedalus 106: 61-80

Van Manen, M. 1990. Researching Lived Experience. State University of New York: USA. 